\title{
Diversities of Sexual Activities and Correlates of Safe Sex Practices Among Adolescents in Plateau State, Nigeria
}

\author{
Esther Awazzi Envuladu ${ }^{1,2 \star}$, Karlijn Massar ${ }^{3}$ and John B. F. de Wit ${ }^{2}$ \\ ${ }^{1}$ Department of Community Medicine, College of Health Sciences, University of Jos, Jos, Nigeria, ${ }^{2}$ Department of \\ Interdisciplinary Social Science, Utrecht University, Utrecht, Netherlands, ${ }^{3}$ Department of Work and Social Psychology, \\ Maastricht University, Maastricht, Netherlands
}

OPEN ACCESS

Edited by:

Juliet Iwelunmor-Ezepue, Saint Louis University, United States

Reviewed by:

Kim Jonas,

South African Medical Research Council, South Africa

Ucheoma Catherine Nwaozuru, Saint Louis University, United States

*Correspondence:

Esther Awazzi Envuladu esvula@gmail.com

Specialty section:

This article was submitted to Adolescent Reproductive Health and

Well-being,

a section of the journal

Frontiers in Reproductive Health

Received: 20 July 2021 Accepted: 20 October 2021 Published: 12 November 2021

Citation:

Envuladu EA, Massar $K$ and de Wit JBF (2021) Diversities of Sexual Activities and Correlates of Safe Sex

Practices Among Adolescents in Plateau State, Nigeria. Front. Reprod. Health 3:744622. doi: 10.3389/frph.2021.744622
Background: Unsafe sex, particularly, condomless sex exposes adolescents to sexual and reproductive health risks. This study aimed to assess the sexual experiences and to determine the most important covariates of sexual activity and consistent condom use among adolescents in Plateau State, Nigeria.

Methods: A cross sectional survey was conducted among 428 adolescents selected from 6 LGAs through a multistage sampling technique. The data was analyzed using the IBM Statistical package for Social Sciences (SPSS) version 23, multiple logistic regression was conducted to determine the covariates of sexual activity and condom use.

Results: About one third (38\%) of the adolescents were sexually active, 5.7\% had same sex partners, $70 \%$ had more than one sexual partner and majority $(72.4 \%)$ were not consistently using condom during sex. Logistic regression results showed that older adolescents $(\mathrm{OR}=5.73 ; \mathrm{Cl}=3.72-8.12 ; p=0.001)$ and out of school adolescents $(\mathrm{OR}=2.68 ; \mathrm{Cl}=1.79-4.00 ; p=0.001)$ were more likely to be sexually active, while multivariable logistic regression analysis showed age $(A O R=0.33 ; \mathrm{Cl}=0.12-0.90$; $p=0.031)$ and gender as important covariates of being sexually active, $(A O R=6.29 ; \mathrm{Cl}$ $=3.18-12.44 ; p=0.001)$. Inconsistent condom use was more likely among adolescents; with lower education, $(\mathrm{OR}=2.14 ; \mathrm{Cl}=1.19-3.85 ; p=0.011)$, having sex with older partners $(\mathrm{OR}=0.61 ; \mathrm{Cl}=0.42-0.90 ; P=0.013)$ and with low awareness of $\mathrm{SRH}$ issues $(\mathrm{OR}=2.08 ; \mathrm{Cl}=1.02-4.22 ; p=0.044)$. The multivariable logistic regression however, showed gender, being male $(\mathrm{AOR}=0.43 ; \mathrm{Cl}=0.006-3.09 ; p=0.023$ ) as covariate of consistent condom use.

Conclusion: Most sexually active adolescents had multiple sexual partners, some had same sex partners and majority were not consistently using condom. Older adolescents and those out of school were more likely to be sexually active. Awareness of SRH issues significantly influenced condom use while gender, specifically being male, was the independent covariate for being sexually active and for consistent condom use. We recommend sexual health intervention targeted at adolescents. In addition, gender should be mainstreamed into adolescent sexual and reproductive health programmes.

Keywords: adolescent, sexual diversity, consistent condom use, Plateau State, Nigeria 


\section{INTRODUCTION}

Adolescence is a period of major developmental transitions, marked by physiological, physical and emotional changes, and the acquisition of advanced impulse regulation (1). Together, these changes have a profound influence on adolescent's decision making, risk taking, and social relationships (1). Adolescence is also a critical period for romantic and sexual development, and across the world, adolescents are known to become sexually active and gain diverse sexual experiences (2). As elsewhere, a significant proportion of adolescents in Nigeria are sexually active, and the sexual conduct of adolescents in Nigeria has similarly attracted public health concerns, particularly because of the high prevalence of unsafe sex, mainly condomless sex among this age group (3).

Sex without a condom is the major unsafe practice which exposes adolescents to various risks, such as unintended pregnancy, early child birth and unsafe abortion, and also puts them at a high risk of contracting sexually transmitted infections (STIs), including HIV $(4,5)$. Adolescent pregnancy is a public health challenge in Africa, and adolescent pregnancies are one of the major reasons for the high rate of maternal mortality in Nigeria (6). A systematic review and meta-analysis estimated a pooled adolescent pregnancy rate of $18.8 \%$ in Africa, $19.3 \%$ in Sub-Saharan African, and $15.9 \%$ in Nigeria (6). Recent data has shown an upward trajectory in the rates of STIs, notably gonorrhea, chlamydia, and human papilloma virus infection among adolescents and young people (7). While the HIV epidemic appears to be decreasing in Nigeria and other African countries, this gain is limited and there is evidence that HIV prevalence is still high among adolescents and young people and AIDS remains a leading cause of mortality among young people in Africa $(7,8)$.

Condom use, which is one of the most cost effective protective measures against unintended pregnancy and STI/HIV is underpinned by complex factors. Research has found that social, economic and cultural factors are related to condomless sex (9-13). Gender dynamics are important drivers of noncondom use because of the inability of both partners to openly communicate safe sex, due to the power differences that exist between males and females in Africa (14). Also, early sexual initiation, having multiple sexual partners and intergenerational sex, that is, a sexual relationship with an older partner are factors found to be associated with inconsistent condom use among adolescents in some studies $(15,16)$. In many cases, sex with older partners is transactional, in exchange for material, money and other benefits. In Nigeria, transactional sex is a common practice among adolescent girls as well as boys, and this poses a challenge for adolescents to negotiate protective options such as consistent (i.e., at every sexual intercourse) condom use (9, 17, 18). Aside the challenge adolescents have negotiating condom use with older partners; consistent condom use is linked to adolescent's (lack of) awareness/knowledge of SRH issues, and risk perception regarding STIs, HIV, and pregnancy (19-21). Research in several sub-Sahara African countries (e.g., Nigeria, South-Africa, Zimbabwe, Mozambique) found that adolescent's low perceived risk of HIV or other STIs contributes significantly to their likelihood of not (consistently) using a condom during sexual intercourse (22-25).

The risk perception may also be due to lack of adequate knowledge on sexual and reproductive health matters subsequent to poor communication between parents and adolescents on sexuality issues (26). Like in many African countries, adolescent sexual behavior is a sensitive matter in the context of dominant religion and culture $(27,28)$.

Parents in Nigeria sometimes deny adolescent involvement in sex outside marriage and typically adhere to strict, traditional discipline in the upbringing of their children that makes it difficult to accept that adolescents may have sex (29). In contrast, most adolescents are exposed to information about sex through the Internet (27), and frequently engage in (unsafe) sex (2, 27). Although the Nigerian government made a commitment to provide ASRH services to address adolescent's sexual and reproductive health issues, these services are often not availableand when they are, they are of low quality and do not meet adolescent's needs (30).

As most young people become sexually active in adolescence, including in Nigeria, it is important to prevent adverse outcomes and promote the sexual health and well-being of adolescents. This study therefore aimed to assess the sexual experiences of adolescents in Plateau State, Nigeria, and to examine sociodemographic characteristics and awareness of SRH issues, knowledge of prevention of SRH problems, and perceived risk of SRH problems as covariates of their sexual activity and safe sex practices, specifically consistent condom use. The findings from this study may inform governmental policy development and decision-making regarding the provision and implementation of adolescent sexual and reproductive health care services across Nigeria.

\section{METHODS}

\section{Study Design and Setting}

A cross sectional survey was conducted among adolescents 1819 years who resided in Plateau State, one of the 36 States in Nigeria, located in the central part of the country. Plateau State has an estimated population of $4,376,193$, of which about $23 \%$ are adolescents. In Nigeria, states are broadly divided into 3 senatorial zones and geographically divided into local government areas (LGA), the LGAs are further divided into political wards which is also recognized by WHO. There are 17 LGA in Plateau State, and three senatorial zones; the Northern senatorial zone has six LGAs, the Central zone has five LGAs, and the Southern zone consists of six LGAs. The current study was conducted in 6 LGAs, two LGAs in each of the three senatorial zones.

\section{Participants and Recruitment}

The sample size was determined using the Cochran formula $\left(n_{0}\right.$ $\left.=\mathrm{Z}^{2} \mathrm{pq} / \mathrm{e}^{2}\right)$, (31) where $\mathrm{n}$ is the minimum sample size, $\mathrm{Z}$ is the standard normal deviate which corresponds to a $95 \%$ confidence interval (1.96), $\mathrm{p}$ is the proportion of adolescents who are sexually active, here assumed to be $50 \%$, q is the complimentary 
probability (1-p), and e is the $5 \%$ margin of error. A minimum sample size of 384 was determined based on this calculation.

Participants were recruited through a multistage sampling technique. First, two LGAs were selected using a simple random sampling technique by balloting from the list of LGAs in each of the senatorial zones, giving a total of 6 LGAs. Next, from each of these six LGAs, three wards were randomly selected from approximately 15 wards in each LGA by balloting. At the ward level, the research team collaborated with community mobilizers (i.e., local government staff that serve as community liaison officers) and youth leaders (i.e., the official representatives of organized youth groups in each ward) to identify houses with adolescents aged 18-19 years that could participate in the study, total sampling of all the houses with eligible adolescents was done. A team of research assistants who were medical students aged 19-22 years collected the data by going from house to house and asking eligible adolescents who gave consent to participate. The research assistants received training in data collection for the study, which included practical demonstrations and undertaking pretesting of the questionnaire in a different community setting before the actual data collection. In total, 1,008 houses were visited. Where more than one adolescent was present in the household, balloting was used to select one adolescent. A total of $\mathrm{n}=479$ adolescents gave consent and participated in the study; 428 questionnaires were completely filled out and eligible for inclusion in the analyses.

\section{Measures}

Socio-demographic characteristics included age, gender, marital status, schooling status (in school or out of school) and highest level of educational qualification.

Diverse sexual experiences of adolescents assessed included being in an intimate relationship, being sexually active (i.e., currently having sex with someone), those sexually active were asked age at sexual debut; gender of sexual partner(s) i.e. same sex or opposite sex, age of sexual partner(s), marital status of sexual partner(s), and number of sexual partners.

Consistent condom use during sex was specifically asked among those who were sexually active by asking if condom was used at every sexual intercourse. Those who indicated to always use condom were considered as consistent condom use while those who responded to never or not always using a condom were considered inconsistent condom use.

Awareness of SRH issues were assessed by three questions, with responses indicated as yes (scored 1) or no (scored 0 ): "Have you heard about sexual and reproductive health?" "Have you heard about STI?" and "Have you heard about HIV?" The total scores for level of awareness ranged from 0 to 3 .

Knowledge of prevention of SRH problems was assessed by asking if they knew how to prevent pregnancy, STI and HIV, those who answered yes to any of the three questions were further asked to mention specific methods of prevention of pregnancy, STI and HIV. Appropriate responses (i.e., the use of condom for prevention of pregnancy, STI and HIV or the use of contraceptives for prevention of pregnancy) was scored 1 each, whereas those who gave inappropriate responses were scored 0 ; total scores ranged from 0 to 3 . Those who scored $\leq 1$ were considered to have poor knowledge, those who scored 2 were considered to have fair knowledge, and those who scored 3 were considered to have good knowledge.

Perceived risk of becoming pregnant, becoming infected with STI or with HIV during condomless sex was assessed with three questions: "Do you think you are at risk of pregnancy during unprotected sex?" "Do you think you are at risk of sexually transmitted infection during unprotected sex?" and "Do you think you are at risk of HIV infection during unprotected sex?" Total scores ranged from 0 to 3, those who responded that they were not at risk during unprotected sex were scored 0 while those who responded that they were at risk during unprotected sex were scored 1 . The scores of 0 or 1 were considered low risk perception, whereas scores of 2 or 3 were considered high risk perception.

\section{Data Analysis}

Frequency analysis was used to describe the socio-demographic characteristics of adolescents, as well as their diverse sexual experiences, their awareness of SRH issues, knowledge of prevention of SRH problems, and perceived risk of $\mathrm{SRH}$ problems. Univariate and multivariable logistic regression analyses were conducted to assess covariates of sexual activity and consistent condom use. The data were analyzed using the IBM Statistical package for Social Sciences (SPSS), version 23.

\section{Ethical Approval}

Ethical clearance was obtained from the Jos University Teaching Hospital (JUTH) Human and Research Ethics Committee, and permission was obtained from the Plateau State Ministry of Health, the selected LGA authorities and the village heads of the various communities in the selected wards before commencement of the study. Written informed consent was obtained from the participants after a detailed explanation of the study.

\section{RESULTS}

\section{Participant Characteristics}

Slightly more males than females participated in the study $(51.9 \%$ males and $48.1 \%$ females) $52.3 \%$ were 18 years old and $47.7 \%$ were 19 years; $5.8 \%$ of the respondents were married adolescents and $41.1 \%$ of the respondents were out of school at the time of the study while $11.7 \%$ of the adolescents had no formal education or just a primary level of education (see Table 1).

\section{Sexual Diversities and Sexual Risk Behavior}

More than half of the respondents (57.2\%) indicated they were in an intimate relationship and $38.1 \%$ were sexually active at the time of the study. Respondent's age at sexual debut ranged from 6 to 19 years, and the mean age at sexual debut was 15.9 years $(\mathrm{SD}=$ 2.94). The majority had sexual partners of the opposite sex, while $5.7 \%$ (also) had same-sex partners. About $70 \%$ had more than one sexual partner, $40 \%$ had $2-3$ sexual partners, and $15.3 \%$ had more than 5 sexual partners. Majority (72.4\%) of the sexually active adolescents were not consistently using condom during sex. and 
TABLE 1 | Socio-demographic characteristics of participating adolescents in Plateau State, Nigeria $(N=428)$.

\begin{tabular}{|c|c|c|}
\hline Socio-demographic characteristics & Frequency & $\%$ \\
\hline \multicolumn{3}{|l|}{ Gender } \\
\hline Male & 222 & 51.9 \\
\hline Female & 206 & 48. \\
\hline \multicolumn{3}{|l|}{ Age in years } \\
\hline 18 & 224 & 52.3 \\
\hline 19 & 204 & 47.7 \\
\hline \multicolumn{3}{|l|}{ Marital status } \\
\hline Married & 25 & 5.8 \\
\hline Not married & 403 & 94.2 \\
\hline \multicolumn{3}{|l|}{ Religion } \\
\hline Christianity & 357 & 83.4 \\
\hline Islam & 71 & 16.6 \\
\hline \multicolumn{3}{|l|}{ Schooling status } \\
\hline In school & 252 & 58.9 \\
\hline Out of school & 176 & 41.1 \\
\hline \multicolumn{3}{|l|}{ Educational level } \\
\hline No formal/primary education & 50 & 11.7 \\
\hline Secondary education & 317 & 74 \\
\hline Tertiary education & 61 & 14.3 \\
\hline
\end{tabular}

most respondent's (61.3\%) had low risk perception, just about half had good awareness of SRH issues (51.5\%), and knowledge of prevention of SRH problems (58.9\%) (see Table 2).

\section{Co-variates of Being Sexually Active}

As shown in Table 3, univariate logistic regression analyses showed that older adolescents were more likely to be sexually active than the younger adolescents $(\mathrm{OR}=5.73$; $\mathrm{CI}=3.72-$ 8.12; $p=0.001$ ), those out of school were more likely to be sexually active than those in school $(\mathrm{OR}=2.68$; $\mathrm{CI}=1.79-4.00$; $p=0.001$ ), and those who were not in any intimate relationship were unlikely to be sexually active $(\mathrm{OR}=0.14$; $\mathrm{CI}=0.09-2.2$; $p=0.001)$. Multivariable logistic regression analysis showed that male gender $(\mathrm{AOR}=0.33 ; \mathrm{CI}=0.12-0.90 ; p=0.031)$, older age $(\mathrm{AOR}=6.29 ; \mathrm{CI}=3.18-12.44 ; p=0.001)$ and being in an intimate relationship $(\mathrm{AOR}=0.08 ; \mathrm{CI}=0.03-0.23 ; p=0.001)$ were covariate of being sexually active, schooling status $(p=$ $0.580)$ and educational level $(p=0.642)$ were however not found to be significant covariates of being sexually active.

\section{Covariates of Consistent Condom Use}

As shown in Table 4, univariate logistic regression analyses showed that males were more likely to consistently use condoms than females $(\mathrm{OR}=0.44 ; \mathrm{CI}=0.21-0.90 ; p=0.024)$, those with no education/primary education were more unlikely to consistently use condoms compare to those with higher levels of education ( $\mathrm{OR}=2.14 ; \mathrm{CI}=1.19-3.85 ; p=0.011)$, and those with sexual partners within their age group were more likely to consistently use condom compare to those with older sexual partners $(\mathrm{OR}=0.61 ; \mathrm{CI}=0.42-0.90 ; P=0.013)$. Also, participants with higher level of awareness of SRH issues were
TABLE 2 | Sexual experience, risk perceptions and awareness of SRH among adolescents in Plateau State, Nigeria.

\begin{tabular}{|c|c|c|}
\hline Variables & Frequency & Percentage \\
\hline \multicolumn{3}{|c|}{ In intimate relationship $(N=428)$} \\
\hline Yes & 245 & 57.2 \\
\hline No & 183 & 42.8 \\
\hline \multicolumn{3}{|c|}{ Gender of intimate partner $(N=245)$} \\
\hline Opposite sex & 231 & 94.3 \\
\hline Same sex & 14 & 5.7 \\
\hline \multicolumn{3}{|c|}{ Currently Sexually active (245) } \\
\hline Yes & 163 & 38.1 \\
\hline No & 265 & 61.9 \\
\hline \multicolumn{3}{|c|}{ Age at first sexual intercourse(163) } \\
\hline$<10-13$ years & 23 & 14.1 \\
\hline $14-16$ years & 53 & 32.5 \\
\hline $17-19$ years & 87 & 53.4 \\
\hline \multicolumn{3}{|l|}{ Condom use (163) } \\
\hline Inconsistent & 118 & 72.4 \\
\hline Consistent & 45 & 27.6 \\
\hline \multicolumn{3}{|c|}{ Risk perception $(N=163)$} \\
\hline Low risk & 100 & 61.3 \\
\hline High risk & 63 & 38.7 \\
\hline \multicolumn{3}{|c|}{ Awareness of SRH issues } \\
\hline low awareness & 79 & 48.5 \\
\hline high awareness & 84 & 51.5 \\
\hline \multicolumn{3}{|c|}{ Knowledge of prevention of SRH problems } \\
\hline Poor knowledge & 67 & 41.1 \\
\hline Good knowledge & 96 & 58.9 \\
\hline
\end{tabular}

more likely to consistently use condoms than those with lower level of awareness of SRH issues $(\mathrm{OR}=2.08$; $\mathrm{CI}=1.02-4.22$; $p=0.044)$. The multivariable logistic regression analysis however showed male gender $(\mathrm{AOR}=0.43 ; \mathrm{CI}=0.006-3.09 ; p=0.023)$ as the only significant covariate of consistent condom use while age $(p=0.843)$, education $(p=0.102)$, age of sexual partners $(p$ $=0.142)$ and number of sexual partners $(p=0.325)$ were not covariate of consistent condom use.

\section{DISCUSSION}

Young people in Nigeria are at risk of several sexual and reproductive health problems such as unintended pregnancy, STIs, and HIV (6). Therefore, the aims of the current study were to assess the sexual experiences of adolescent boys and girls in Plateau State, Nigeria, to understand the factors that influence their sexual activity, and to determine the most significant covariates of (in)consistent condom use. The latter is an important contributing factor for mitigating the health risks these young people are exposed to.

Our results show that although the majority had sexual partners of the opposite sex, few of the adolescents had same sex partners. In addition, more than three quarter of the sexually active adolescents were not consistently using condoms during sex. This is especially concerning because more than half of 
TABLE 3 | Covariates of being sexually active among adolescents in Plateau State, Nigeria ( $N=428)$.

\begin{tabular}{|c|c|c|c|c|c|c|c|c|}
\hline & \multicolumn{2}{|c|}{ Sexually active } & \multirow[b]{2}{*}{ OR } & \multirow[b]{2}{*}{$95 \% \mathrm{Cl}$} & \multirow[b]{2}{*}{$\mathbf{p}$} & \multirow[b]{2}{*}{ AOR } & \multirow[b]{2}{*}{$95 \% \mathrm{Cl}$} & \multirow[b]{2}{*}{$p$} \\
\hline & Yes & No & & & & & & \\
\hline \multicolumn{9}{|l|}{ Gender } \\
\hline Male & 85(38.3) & $137(61.7)$ & 0.98 & $0.67-1.45$ & 0.928 & 0.33 & $0.12-0.90$ & 0.031 \\
\hline Female & 78(37.9) & $128(62.1)$ & & & & & & \\
\hline \multicolumn{9}{|l|}{ Age } \\
\hline 18 years & 44(19.6) & $180(80.4)$ & 5.73 & $3.72-8.12$ & 0.001 & 6.29 & $3.18-12.44$ & 0.001 \\
\hline 19 years & $119(58.3)$ & $85(41.7)$ & & & & & & \\
\hline \multicolumn{9}{|l|}{ Marital status } \\
\hline Married & $16(64.0)$ & $9(36.0)$ & 0.32 & $0.14-0.75$ & 0.008 & 0.21 & $0.06-0.81$ & 0.023 \\
\hline Not married & $147(36.5)$ & 256(63.5) & & & & & & \\
\hline \multicolumn{9}{|l|}{ Schooling status } \\
\hline In school & $72(28.6)$ & $180(71.4)$ & 2.68 & $1.79-4.00$ & 0.001 & 1.21 & $0.62-2.36$ & 0.58 \\
\hline Not in school & $91(51.7)$ & 85(48.3) & & & & & & \\
\hline \multicolumn{9}{|l|}{ Education level } \\
\hline No formal or primary education & $27(54.0)$ & 23(46.0) & 1.25 & $0.85-1.84$ & 0.256 & 1.11 & $0.71-1.74$ & 0.642 \\
\hline Secondary education & $99(31.2)$ & 218(68.8) & & & & & & \\
\hline Tertiary education & $37(60.7)$ & 24(39.3) & & & & & & \\
\hline \multicolumn{9}{|l|}{ In intimate relationship } \\
\hline Yes & $136(55.5)$ & $109(44.5)$ & 0.14 & $0.09-2.2$ & 0.001 & 0.08 & $0.03-0.23$ & 0.001 \\
\hline No & $27(14.8)$ & 156(85.2) & & & & & & \\
\hline
\end{tabular}

our respondents indicated a low risk perception for unintended pregnancies or disease transmission. Further, almost half of the adolescents had a low level of awareness of SRH issues and poor knowledge of how to prevent pregnancy, STI and HIV. These findings are corroborated by similar studies, for example, a meta-analysis of research in sub-Saharan African countries and Nigeria reported high rates of sexual activity and multiple sexual partners among adolescents males and females, as well as a large age difference between adolescents and their sexual partners (32-34). Also, studies conducted among adolescents in Nigeria have reported inconsistent use of condoms during sex, as well as a low risk perception and lack of knowledge of SRH issues and how to prevent SRH problems $(11,12,22)$.

Our results show that older adolescents were five times likely to be sexually active than younger ones, adolescents out of school were twice as likely to be sexually active than those in school, and males were more likely to be sexually active than females. This is in line with studies conducted in the western and Eastern part of Nigeria $(35,36)$. Moreover, gender (i.e., being male) was an important factor linked to the sexual activity of adolescents in three consecutive demographic and health surveys in Nigeria (34). Some studies have also linked the role of gender in sexual activity especially in Africa to the patriarchal norms; where males are seen as superior to females and permitted by society to always have their ways, this dominant role exert influence on their sexual behavior $(1,37)$.

Factors found to be associated with inconsistent condom use in this study were a lower level of education and having sex with older partners: Adolescents with a lower level of education were twice as likely to have inconsistent condom use during sex compared to those with a higher education, while those who reported to have sexual partners within their own age group were more likely to consistently use a condom during sex. Similarly, some studies have documented inconsistent condom use among adolescents in relationship with older partners; the younger partners usually find it difficult to persuade the older partners especially when the partners are unwilling to use condom (37-39). However, the one unique covariate of consistent condom use in this study is gender; the adolescent males were more likely to consistently use condom during sex than the female adolescents. Similar to our finding is the results from studies in some African countries and across Nigeria, which also reported more condomless sex among females, attributing it to gender inequality which does not encourage free dialogue and communication between partners (37, 40-42).

One of the strength of this study is the privacy and confidentiality provided during data collection. Specifically, were the research assistances that were their age group that gave the respondents the freedom to provide information on their sexual life more freely. Furthermore, the diversity of the adolescents (males and females, in-school and out of school, lower education and higher education) in this study gave a broader perspective of the sexual experiences and the factors influencing condom use among adolescents. The study however did not capture the younger adolescents, mainly due to ethical reasons around consent when conducting studies among younger adolescents, thereby limiting our understanding of the particular experiences 
TABLE 4 | Covariates of consistent condom use among sexually active adolescents in Plateau State $(N=163)$.

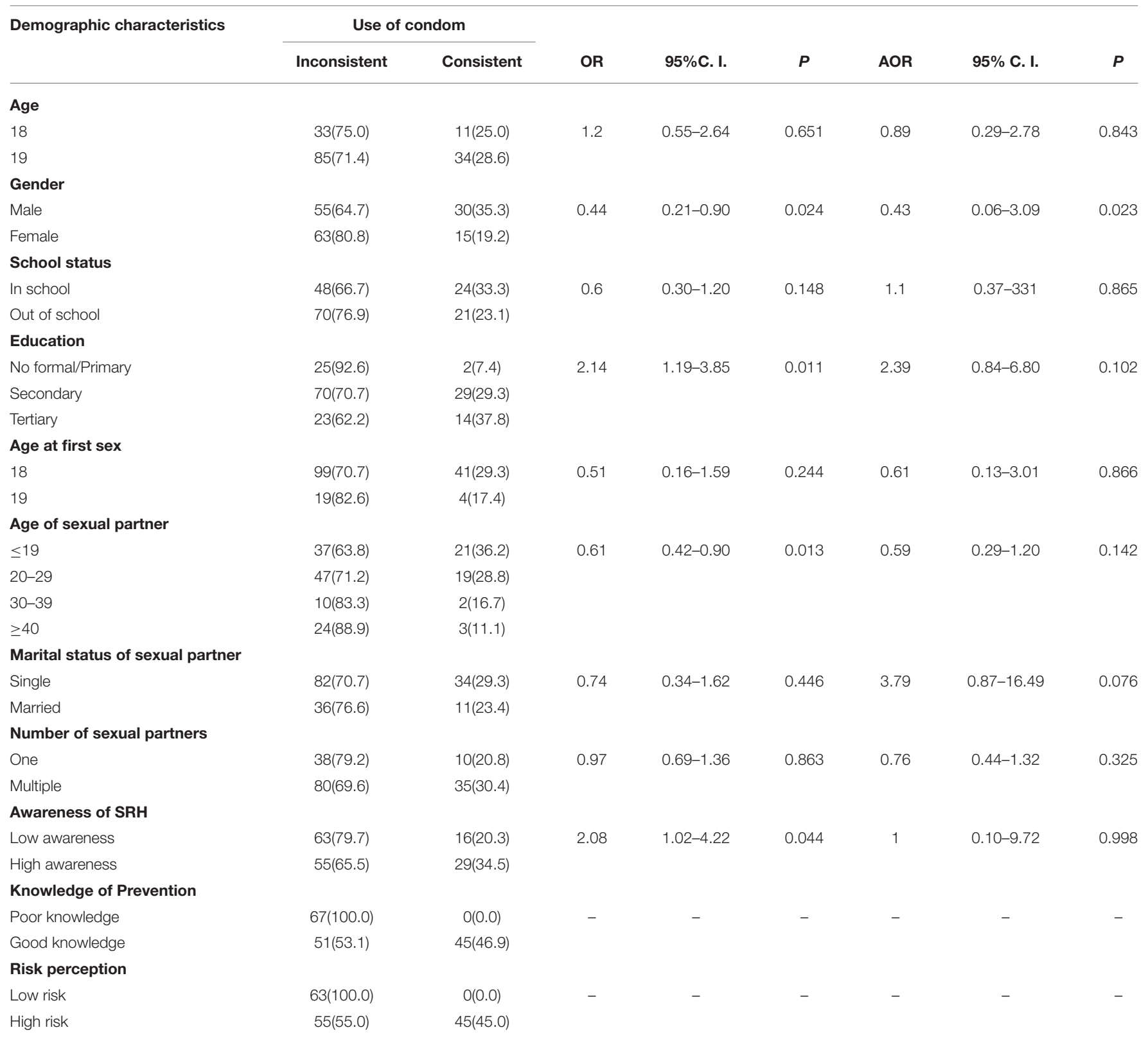

OR for the last two variables cannot be computed because condom consistency is zero.

and challenges of this younger group of adolescents. We are also not ruling out recall bias from self-reporting and social desirability bias in reporting sexual activity though they were asked to be honest in their responses and assured of confidentiality.

\section{CONCLUSION AND RECOMMENDATIONS}

In this study, we found that a good number of adolescents were sexually active with diverse experiences. Both male and female adolescents had multiple sexual partners and some had same sex partners. The majority of the sexually active adolescents had low risk perception and were not consistently using condom during sex. We also found that more than half of the adolescents had low risk perception of getting pregnant/becoming infected with STI or HIV during unprotected sex and about half were not aware of SRH issues. Gender was seen to significantly influence safe sex, specifically being male, was the independent covariate for being sexually active and for consistent condom use.We recommend that more sexual health promotion activities geared toward safe sex practices be targeted at both in school and out of school adolescents. In addition, gender should be mainstreamed into ASRH programmes to ensure a better and healthier sexual experience among adolescents. 


\section{DATA AVAILABILITY STATEMENT}

The raw data supporting the conclusions of this article will be made available by the authors, without undue reservation.

\section{ETHICS STATEMENT}

The studies involving human participants were reviewed and approved by Jos University Teaching Hospital (JUTH)

\section{REFERENCES}

1. Folayan MO, Odetoyinbo M, Brown B, et al. Differences in sexual behaviour and sexual practices of adolescents in Nigeria based on sex and self-reported HIV status. Reprod Health. (2014) 11:83. doi: 10.1186/1742-4755-11-83

2. Afriyie J, Essilfie ME. Association between risky sexual behaviour and HIV risk perception among in-school adolescents in a municipality in Ghana. Ghana Med J. (2019) 53:29-36. doi: 10.4314/gmj.v53i1.5

3. Aji J, Aji M, Ifeadike C, Emelumadu O, Ubajaka C, Nwabueze S, et al. Adolescent Sexual behaviour and practices in Nigeria: a twelve year review. Afrimedic Journal. (2013) 4:10-f16.

4. Shiferaw Y, Alemu A, Assefa A, Tesfaye B, Gibermedhin E, Amare M. Perception of risk of HIV and sexual risk behaviors among university students: implication for planning interventions. BMC Res Notes. (2014) 7:1-8. doi: 10.1186/1756-0500-7-162

5. Kassahun EA, Gelagay AA, Muche AA, Dessie AA, Kassie BA. Factors associated with early sexual initiation among preparatory and high school women in Woldia town, Northeast Ethiopia: a cross sectional study. BMC Public Health. (2019) 19:378. doi: 10.1186/s12889-019-6682-8

6. Kassa GM, Arowojolu AO, Odukogbe AA, Yalew AW. Prevalence and determinants of adolescent pregnancy in Africa: a systematic review and meta-analysis. Reprod Health. (2018) 15:195. doi: 10.1186/s12978-018-0640-2

7. UNICEF. HIV and AIDS in Adolescents. (2019). Available online at: https:// datauniceforg/topic/adolescents/hiv-aids/ (access October 28, 2020)

8. NACA. National HIV Strategy for Adolescents and Young People NACA Nigeria. Available online at: https://naca.gov.ng/national-hiv-strategyadolescents-young-people/ (access October 28, 2020)

9. Ajayi AI, Somefun OD. Transactional sex among Nigerian university students: the role of family structure and family support. PLoS ONE. (2019) 14:e0210349. doi: 10.1371/journal.pone.0210349

10. Onayade A, Abiona T, Ugbala C, Alozie G, Adetuyi O. Determinants of consistent condom use among adolescents and young adults attending a tertiary educational institution in Ile-Ife, Nigeria. Niger Postgrad Med J. (2008) 15:185-91.

11. Ajayi AI, Ismail KO, Akpan W. Factors associated with consistent condom use: a cross-sectional survey of two Nigerian universities. BMC Public Health. (2019) 19:1207. doi: 10.1186/s12889-019-7543-1

12. Odimegwu C, Somefun OD. Ethnicity, gender and risky sexual behaviour among Nigerian youth: an alternative explanation. BMC Reproductive Health. (2017) 14:16. doi: 10.1186/s12978-017-0284-7

13. AFRICAN UNION. The Effects of Traditional and Religious Practices of Child Marriage on Africa's Socio-Economic Development (2015).

14. Melesse DY, Mutua MK, Choudhury A, Wado YD, Faye CM, et al. Adolescent sexual and reproductive health in sub-Saharan Africa: who is left behind? BMJ Global Health. (2020) 5:e002231. doi: 10.1136/bmjgh-2019-0 02231

15. Imaledo JA, Peter-Kio OB, Asuquo EO. Pattern of risky sexual behavior and associated factors among undergraduate students of the University of Port Harcourt, Rivers State, Nigeria. Pan Afr Med J. (2012) 9:97.

16. Ayamolowo SJ, Ayamolowo LB, Afolabi EK. Knowledge and behavioural intentions for intergenerational sexual relationships among young female students in a pre-varsity institution in Southwest Nigeria. Women Health Bull. (2020) 7:2-10.
Research Ethics Committee. The patients/participants provided their written informed consent to participate in this study.

\section{AUTHOR CONTRIBUTIONS}

All authors listed have made a substantial, direct and intellectual contribution to the work, and approved it for publication.
17. Dana LM, Adinew YM, Sisay MM. Transactional sex and HIV risk among adolescent school girls in Ethiopia: mixed method study. Biomed Res Int. (2019) 2019:4523475. doi: 10.1155/2019/4523475

18. Ajayi AI, Ismail KO, Adeniyi OV, Akpan W. Awareness and use of pre-exposure and postexposure prophylaxes among Nigerian university students: findings from a cross-sectional survey. Medicine. (2018) 97:e12226. doi: 10.1097/MD.0000000000012226

19. Odeigah L, Rasaki SO, Ajibola AF, Ameen AH, Sule AG, Musah Y. High risk sexual behavior among adolescent senior secondary school students in Nigeria. Afr Health Sci. (2019) 19:1467-77. doi: 10.4314/ahs.v19i1.20

20. Ajide, KB. Balogun FM. Knowledge of HIV and intention to engage in risky sexual behaviour and practices among senior school adolescents in Ibadan, Nigeria. Arch Basic Appl Med. (2018) 6:3-8.

21. Oster E. HIV and sexual behaviour change: why not Africa? J Health Econ. (2012) 31:35-49. doi: 10.1016/j.jhealeco.2011.12.006

22. Olajide FO, Olajide AO, Olowookere SA, Omisore AG. Factors associated with inconsistent condom use and multiple sexual partners among adolescents in South Western, Nigeria. Afr J Med Med Sci. (2020) 49:447-58.

23. Muchiri E, Odimegwu C, De Wet N. HIV risk perception and consistency in condom use among adolescents and young adults in urban Cape Town, South Africa: a cumulative risk analysis. South Afr J Infect Dis. (2017) 32:105110. doi: 10.1080/23120053.2017.1332800

24. Espada, J.P., Morales, A., Guillén-Riquelme, A, Ballester R, Orgiles M. Predicting condom use in adolescents: a test of three socio-cognitive models using a structural equation modeling approach. BMC Public Health. (2016) 16 : 35 doi: 10.1186/s12889-016-2702-0

25. Dallo L, Martins RA. Association between risk behaviors of alcohol use and unprotected sex in adolescents in a city in southern Brazil. Ciênc Saúde saúde. (2018) 23:303-14. doi: 10.1590/1413-81232018231.14282015

26. Motsomi K, Makanjee C, Basera T, Nyasulu P. Factors affecting effective communication about sexual and reproductive health issues between parents and adolescents in zandspruit informal settlement, Johannesburg, South Africa. Pan Afr Med J. (2016) 25:120. doi: 10.11604/pamj.2016.25.120.9208

27. Baku EA, Agbemafle I, Kotoh AM, Adanu RMK. Parent's experiences and sexual topics discussed with adolescents in the Accra Metropolis, Ghana: a qualitative study. Adv Public Health. (2018) 2018:1-12. doi: $10.1155 / 2018 / 5784902$

28. Mbachu CO, Agu IC, Eze I, Agu C, Ezenwaka U, Ezumah N, et al. Exploring issues in caregivers and parent communication of sexual and reproductive health matters with adolescents in Ebonyi state, Nigeria. BMC Public Health. (2020) 20, 77. doi: 10.1186/s12889-019-8058-5

29. Odebode AA. Parental attitude towards sexuality education for secondary school students in Kwara State, Nigeria. Anatol J educ. (2019) 4:7784. doi: 10.29333/aje.2019.417a

30. Envuladu EA, Massar, K. deWit, J. Adolescent Sexual and Reproductive Health Care Service Availability and Delivery in Public Health Facilities of Plateau State Nigeria. Int J Environ Res Public Health. (2021) 18:1369. doi: 10.3390/ijerph18041369

31. Cochran WG. Sampling Techniques. 3rd ed. New York, NY: Wiley (1977)

32. Schaefer R, Thomas R, Maswera R, Kadzura N, Nyamukapa C, Gregson S. Relationships between changes in HIV risk perception and condom use in East Zimbabwe 2003-2013: population-based longitudinal analyses. BMC public health. (2020) 20:1-14. doi: 10.1186/s12889-020-08815-1 
33. Furlanetto, M.F, Ghedin, D.M., Gonçalves, T.R, Marin A.H. Individual and contextual factors associated with sexual initiation among adolescents. Psicol. Refl Crít. (2019) 32: 25 doi: 10.1186/s41155-019-0138-Z

34. Shayo FK, Kalomo MH. Prevalence and correlates of sexual intercourse among sexually active in-school adolescents: an analysis of five sub-Sahara African countries for the adolescent's sexual health policy implications. BMC Public Health. (2019) 19:1285. doi: 10.1186/s12889-019-7632-1

35. Odii A, Atama CS, Igwe I, Idemili-Aronu NJ. Onyeneho NG. Risky sexual behaviours among adolescent undergraduate students in Nigeria: does social context of early adolescence matter? Pan Afr Med J. (2020) 37:188. doi: 10.11604/pamj.2020.37.188.22968

36. Dogu P, Udigwe I, Nwabueze A, Adinma E, Udigwe G, Onwasigwe C. Sexual health knowledge, attitude and risk perception among in-school and out-ofschool female adolescents in Onitsha, Anambra State, Nigeria. South East Eur J Public Health (SEEJPH). (2014) 2:1-11. doi: 10.4236/asm.2014.43007

37. Amo-Adjei J. Age differences and protected first heterosexual intercourse in Ghana. Afr J Reprod Health. (2012)16:58-67.

38. Dietrich J, Sikkema K, Otwombe KN, et al. Multiple levels of influence in predicting sexual activity and condom use among adolescents in Soweto, Johannesburg, South Africa. J HIV AIDS Soc Serv. (2013) 12:404-23. doi: 10.1080/15381501.2013.8 19312

39. Morris L, Kouya F, Kwalar R, Pilapil M, Saito K, Palmer N, et al. Factors associated with inconsistent condom use in adolescents with negative or unknown HIV status in Northwest Cameroon. AIDS Care. (2014) 26:14405. doi: 10.1080/09540121.2014.920948

40. Katikiri E, Njau B. Motivating Factors and psychosocial barriers to condom use among out-of-school youths in Dar es Salaam, Tanzania: a cross sectional survey using the health belief model. ISRN AIDS. (2012) 2012:170739. doi: 10.5402/2012/170739

41. Bhana D, Anderson B. Gender, relationship dynamics and South African girl's vulnerability to sexual risk. Afr J AIDS Res. (2013) 12:25-31. doi: 10.2989/16085906.2013.815408

42. Darteh EKM, Dickson KS, Doku DT. Women's reproductive health decision-making: A multi-country analysis of demographic and health surveys in sub-Saharan Africa. PLoS One. (2019) 14:e0209985. doi: 10.1371/journal.pone.0209985

Conflict of Interest: The authors declare that the research was conducted in the absence of any commercial or financial relationships that could be construed as a potential conflict of interest.

Publisher's Note: All claims expressed in this article are solely those of the authors and do not necessarily represent those of their affiliated organizations, or those of the publisher, the editors and the reviewers. Any product that may be evaluated in this article, or claim that may be made by its manufacturer, is not guaranteed or endorsed by the publisher.

Copyright (c) 2021 Envuladu, Massar and de Wit. This is an open-access article distributed under the terms of the Creative Commons Attribution License (CC BY). The use, distribution or reproduction in other forums is permitted, provided the original author(s) and the copyright owner(s) are credited and that the original publication in this journal is cited, in accordance with accepted academic practice. No use, distribution or reproduction is permitted which does not comply with these terms. 